\title{
Rapid Decrease of CD16 (Fc $\gamma$ RIII) Expression on Heat-Shocked Neutrophils and Their Recognition by Macrophages
}

\author{
Małgorzata Bzowska, Magda Hamczyk, Anna Skalniak, and Krzysztof Guzik \\ Department of Immunology, Faculty of Biochemistry, Biophysics and Biotechnology, Jagiellonian University, \\ ul. Gronostajowa 7, 30-386 Kraków, Poland \\ Correspondence should be addressed to Krzysztof Guzik, krzysztof.guzik@uj.edu.pl
}

Received 7 December 2010; Accepted 22 February 2011

Academic Editor: K. Miyake

Copyright ( 92011 Małgorzata Bzowska et al. This is an open access article distributed under the Creative Commons Attribution License, which permits unrestricted use, distribution, and reproduction in any medium, provided the original work is properly cited.

\begin{abstract}
Accumulation of neutrophils in the site of inflammation is a typical mechanism of innate immunity. The accumulated neutrophils are exposed to stressogenic factors usually associated with inflammation. Here, we studied response of human peripheral blood neutrophils subjected to short, febrile-range heat stress. We show that 90 min heat stress slowed down the spontaneous apoptosis of neutrophils. In the absence of typical markers of apoptosis the heat-shocked neutrophils induced antiinflammatory effect in human monocyte-derived macrophages (hMDMs), yet without being engulfed. Importantly, the expression of Fc $\gamma$ RIII (CD16) was sharply reduced. Surprisingly, concentration of the soluble CD16 did not change in heat-shocked neutrophil supernates indicating that the reduction of the cell surface CD16 was achieved mainly by inhibition of fresh CD16 delivery. Inhibitors of $90 \mathrm{kDa}$ heat shock protein (HSP90), a molecular chaperone found in membrane platforms together with CD16 and CD11b, significantly increased the observed effects caused by heat shock. The presented data suggest a novel systemic aspect of increased temperature which relies on immediate modification by heat of a neutrophil molecular pattern. This effect precedes cell death and may be beneficial in the initial phase of inflammation providing a nonphlogistic signal to macrophages before it comes from apoptotic cells.
\end{abstract}

\section{Introduction}

Neutrophilic polymorphonuclear leukocytes (PMNs) are phagocytic cells that constitute the first cellular component of innate immune defense [1]. Quickly reacting to infection and injury, PMNs migrate to sites of inflammation where they eliminate pathogens through professional phagocytosis. However, death or uncontrolled degranulation of PMNs may result in serious tissue injury due to the release of cytotoxic substances accumulated in their phagosomes. In consequence, functional immunity requires that PMNs which happen to be damaged or killed as a result of defect, ageing, or fight with a pathogen, are efficiently removed with minimal collateral damage. Thus PMNs that have emigrated from the bone marrow survive for only $12-36 \mathrm{~h}$ and, if not disturbed by factors of inflammation $[2,3]$, they enter apoptosis and are promptly removed by macrophages. Phagocytosis of neutrophils, which became apoptotic in homeostatic conditions constitutes an anti-inflammatory stimulus for macrophages [4]. Disturbance of uptake of apoptotic neutrophils is thought to be pivotal to the level of tissue damage as their nonphlogistic clearance is critical for the resolution of acute inflammation. To safely eliminate neutrophils the macrophages are equipped with a complex system of redundant receptors and polyvalent recognition molecules enabling efficient detection of specific molecular patterns on the dying cell surface $[5,6]$. This sophisticated recognition system not only prevents uncontrolled release of proinflammatory intracellular content of dying cells (which in the case of neutrophils can be extremely harmful), but also serves as an important regulatory function-phagocytosis of apoptotic PMNs by macrophages reprograming the macrophage to an anti-inflammatory phenotype (extensively reviewed in $[7,8])$.

Mechanisms of recognition and engulfment of damaged and dying cells stay in focus of intensive research. Last decade has yielded several unexpected and critical findings in this field. First, it was shown that necrotic cells externalize phosphatidylserine (PS)—a typical "eat me" signal of apoptotic 
cells [9] —which can be recognized through a PS-dependent mechanism in a nonphlogistic manner [10]. Second, it has been demonstrated that cells dying by apoptosis can be highly immunogenic [11], whereas necrotic cells can be less immunogenic than cells undergoing an immunogenic form of apoptosis [12]. And finally, other studies have shown that antigens from apoptotic cells can be effectively crosspresented to CTLs and initiate an immune response [13]. Consequently, the concept of damage-associated molecular patterns (DAMPs) has been proposed to explain the potential immunogenicity of dying, damaged, or stressed cells [14]. DAMPs, comprising several cell-surface molecules, convey precise information to professional phagocytes about the manner of cell death and the causative agent(s). Therefore, we accede to the view that a cell death pathway does not predict whether the outcome will be an immune response or tolerance. Fever, a temporary, regulated increase in core temperature, is widely thought to confer cytoprotection, but the mechanisms underlying these effects are incompletely understood [15]. At cellular level, heat-shock temperatures trigger increased synthesis of a group of highly conserved molecular chaperones called Heat Shock Proteins (HSPs). These proteins protect native conformation of other proteins against misfolding and irreversible multimeric aggregation extensively reviewed in [16-19]. Induction of HSPs in response to stress serves to protect against the initial insult, augment recovery, and produce resistance to subsequent stress in the cell. Elevated expression of HSPs is cytoprotective not only against heat shock-induced HSPs and provide tolerance to a wide array of stressogenic factors and resistance to apoptosis induced by general cytotoxic factors as well as death ligands like TNF- $\alpha$ or FasL [20-23].

While there is a general consensus regarding the phenomenon of dysregulated neutrophil apoptosis during hyperthermia [24-29], some of the available data are conflicting. Nagarsekar et al. [24] found that culturing human PMNs at $39.5^{\circ} \mathrm{C}$ greatly accelerated caspase-dependent apoptotic cell death, thereby identifying a potentially important mechanism that may limit collateral tissue injury during febrile illnesses. Surprisingly, the proportion of apoptotic neutrophils in subjects with recurrent fever episodes and healthy controls has been reported not to differ, suggesting that neutrophil homeostasis can be regulated by heat without typical apoptosis $[26,27]$.

What has yet to be fully ascertained is if heat shock induces alterations to specific prophagocytosis surface markers ("eat me" signals), if heat-associated changes to such cell cycling markers influence subsequent phagocytotic clearance, and if phagocytosis of heat shocked neutrophils results in proinflammatory or in nonphlogistic efferocytosis. Furthermore, many of the heat shock-induced stress proteins, due to their pleiotropic (sometimes antagonistic) activities, could simultaneously induce overlapping pronecrotic and proapoptotic cellular events. This would help explain many discrepancies in the existing data on heat shock-induced cell death in neutrophils where one aspect of cell death has usually been studied in isolation. As our laboratory has focused on recognition and engulfment of apoptotic PMNs, we were vividly interested in modification by heat shock of the neutrophils' molecular patterns and their recognition by macrophages and we set out to examine these concepts.

\section{Materials and Methods}

2.1. Human Monocyte-Derived Macrophages (hMDMs). hMDMs were obtained from PBMC. Briefly, PBMC were isolated from EDTA-treated blood of healthy donors using a Ficoll-Paque PLUS (Amersham Biosciences, Uppsala, Sweden) density gradient and plated at $4 \times 10^{6} / \mathrm{mL}$ in 24 well Primaria cell culture plates (Becton Dickinson, Franklin Lakes, NJ) in RPMI1640 (Gibco Invitrogen Corp., Paisley, UK), supplemented with $2 \mathrm{mM} \mathrm{L}$-glutamine, $50 \mu \mathrm{g} / \mathrm{mL}$ gentamycin (Sigma), and 10\% pooled heat-inactivated human serum, and incubated in a humidified atmosphere containing $5 \% \mathrm{CO}_{2}$ at $37^{\circ} \mathrm{C}$. After 2 hours, nonadherent PBMC were removed by washing plates with complete medium, and adherent cells were then cultured in this medium for at least 7 days. The medium was changed every 2 days. The hMDMs phenotype was routinely controlled, after nonenzymatic detachment of cells, by immunofluorescent staining of CD14 (clone: TÜK4, DakoCytomation Denmark A/S, Glostrup, Denmark), CD16 (clone: DJ130c, DakoCytomation), CD11b (clone: ICRF44, Becton Dickinson and Co., Franklin Lakes, USA), and CD209 (clone: DCN46, Becton Dickinson) and subsequent flow cytometry analysis. The cultures selected for further experiments were positive in at least $90 \%$ for the first three markers and less than $1 \%$ for CD209. The adherent cells acquired typical macrophage morphology and extensive phagocytic activity against live Staphylococcus aureus. Resting (nonstimulated) cells did not produce inflammatory cytokines: IL-1, TNF- $\alpha$, or IL-6.

2.2. Neutrophilic Polymorphonuclear Leukocytes (Neutrophils, $P M N s$ ). PMNs were isolated from erytrosediments by sedimentation in $1 \%$ solution of polyvinyl alcohol (Merck, Hohenbrunn, Germany) for 20 min at room temperature. Neutrophils were collected from the upper part, and contaminated erythrocytes were lysed for $20 \mathrm{sec}$ with water. In such preparation, neutrophils were at least $95 \%$ pure as confirmed by Pappenheim staining.

2.3. Treatment of Neutrophils. Neutrophils were used immediately after isolation (fresh, nonapoptotic). Cells were heat-shocked in a density of $5 \times 10^{6}$ cells per $\mathrm{mL}$, in cell culture medium RPMI1640 supplemented with L-glutamine $(2 \mathrm{mM})$, gentamycin $(50 \mu \mathrm{g} / \mathrm{mL})$, and $10 \%$ heat-inactivated $\left(56^{\circ} \mathrm{C}, 30 \mathrm{~min}\right)$ autologous serum in sealed screw-cap $1.5 \mathrm{~mL}$ microcentrifuge tubes in a controlled heating block (Eppendorf Termomixer Comfort) at indicated temperatures. For inhibition of HSP90, PMNs were incubated with $10 \mu \mathrm{M}$ radicicol or $10 \mu \mathrm{M}$ geldanamycin (both from Sigma) at $37^{\circ} \mathrm{C}$ and then for additional $90 \mathrm{~min}$ at $41^{\circ} \mathrm{C}$. For removal of surface CD16, PMNs were resuspended in culture medium without serum and incubated with $0.5 \mathrm{IU} / \mathrm{mL}$ phosphatidylinositolspecific phospholipase C (PI-PLC, Sigma) for $45 \mathrm{~min}$ at $37^{\circ} \mathrm{C}$. The enzymatic reaction was stopped by serum addition and washing cells in culture medium. In each case control, 
neutrophils were cultured in parallel at $37^{\circ} \mathrm{C}$. Cells were then either directly used or transferred to standard culture conditions for recovery. After treatment, neutrophils were harvested by centrifugation $\left(300 \times \mathrm{g}, 7 \mathrm{~min}, 20^{\circ} \mathrm{C}\right)$ and resuspended in a medium and density suitable for the specific experiment.

For blocking of CD16, PMNs were pretreated with different clones of mAbs specific against different epitopes: Leu11b (BD Pharmingen), 3G8 (BD Pharmingen), Dj130c (Dako), and GRM1 (Abcam). mAbs were added to $1 \times 10^{7}$ PMNs suspended in $1 \mathrm{~mL}$ of RPMI 1640 supplemented with L-glutamine $(2 \mathrm{mM})$, gentamycin $(50 \mu \mathrm{g} / \mathrm{mL})$, and BSA $(0.5 \%)$ at the final concentration $100 \mu \mathrm{g} / \mathrm{mL}$; the cells were incubated for $15 \mathrm{~min}$ at $20^{\circ} \mathrm{C}$, followed by the cytokine production assay performed as described below.

Spontaneous apoptosis in neutrophils was induced by cell incubation for $24 \mathrm{~h}$ in RPMI1640 supplemented with Lglutamine $(2 \mathrm{mM})$, gentamycin $(50 \mu \mathrm{g} / \mathrm{mL})$, and $10 \%$ heatinactivated autologous serum in a humidified atmosphere containing $5 \% \mathrm{CO}_{2}$ at $37^{\circ} \mathrm{C}$. The percentage of cells both annexinVpositive and PInegative in populations of fresh and aged neutrophils ranged from $1 \%$ to $7 \%$ and $45 \%$ to $78 \%$, respectively, whilst the proportion of PIpositive cells did not exceed $15 \%$.

The necrotic death of neutrophils was induced by brief sonication (a hand-held sonicator, model UP50H, Dr Hielscher $\mathrm{GmbH}, 10 \times 1 \mathrm{sec}$ pulse, $50 \mathrm{~W}, 30 \mathrm{kHz}$ ). The effectiveness of process was controlled by trypan blue uptake indicating compromise of the membrane integrity.

2.4. Detection of Cell Death: Flow Cytometry, Membrane Permeabilization, and DNA-Laddering. An early feature of apoptosis, the externalisation of the anionic phospholipid phosphatidyl-serine (PS) was assessed by the binding of FITC-labelled annexin $\mathrm{V}$ and exclusion of propidium iodide according to the manufacturer's recommendations (Annexin V-FITC kit, Bender MedSystems, Vienna, Austria), followed by analysis with an LSRII flow cytometer (Becton Dickinson). Additionally, cellular morphology was evaluated for features of apoptosis or necrosis using bright-field phase contrast microscopy.

The integrity of cellular membranes of neutrophils was monitored by determination of neutrophil elastase (HNE), lactoferrin (LTF), and lactate dehydrogenase (LDH) content in the cell-free culture medium as markers of azurophilic granules, specific granules, and cytosolic fraction, respectively. The assay for NE activity is described in a following section. LTF was measured using Lactoferrin ELISA Kit (Calbiochem), and LDH using Cytotoxicity Detection Kit (Roche) according to Manufacturer's protocols. Additionally, a routine trypan blue exclusion test was applied for quick evaluation of cell viability.

The advanced apoptosis was detected by the presence of the ladder-like DNA fragmentation in control or heatshocked neutrophils. Briefly, cells were suspended in complete culture medium and incubated for $24 \mathrm{hrs}$ in standard culture conditions to allow the development of spontaneous apoptosis. Then, genomic DNA was isolated and gel electrophoresis performed as described previously [30].
2.5. Immunofluorescence Staining of Neutrophils and Flow Cytometry Analysis. For direct immunofluorescence staining, neutrophils $\left(5 \times 10^{5} /\right.$ sample/100 $\left.\mu \mathrm{L}\right)$ were suspended in RPMI 1640 supplemented with 5\% FCS and incubated with PE-conjugated antihuman CD31 (clone WM59, BD Pharmingen), antihuman CD47 (clone B6H12, BD Pharmingen), antihuman CD16 (clone DJ130, Dako), FITCconjugated antihuman Annexin II (clone 5, BD Transduction Laboratories) $\mathrm{mAbs}$, or appropriate isotype controls (BD Pharmingen) for $30 \mathrm{~min}$ at $4^{\circ} \mathrm{C}$. After washing with cold $\mathrm{RPMI} / 5 \% \mathrm{FCS}$, the cells were resuspended in RPMI/5\% FCS. For measurement of Annexin I expression, suspension of neutrophils was incubated with mAb antihuman Annexin I (clone 29, BD Transduction Laboratories) for $30 \mathrm{~min}$ at $4^{\circ} \mathrm{C}$. After washing, cells were incubated with PE-conjugated goat antimouse IgG (BD Pharmingen) for $30 \mathrm{~min}$ at $4^{\circ} \mathrm{C}$, then washed and resuspended in RPMI/5\% FCS. All samples were analyzed by flow cytometry using an LSRII cytometer (Becton Dickinson). Forward and side scatter signals were used to gate for morphologically normal neutrophils, and $10^{4}$ cells were acquired. The analysis was performed using the FACSDiva program to determine the percentage and mean fluorescence intensity of positive cells.

\subsection{Phagocytosis of Neutrophils by hMDMs Using Elastase} Assay. The assay was performed according to the method described in detail by Guzik et al. [31]. Briefly, neutrophils were added to human monocyte-derived macrophages at $2,5 \times 10^{6} \mathrm{cell} /$ well of a 24 -wells plate in the complete medium and incubated for 2 hours at $37^{\circ} \mathrm{C}$ in humidified atmosphere containing $5 \% \mathrm{CO}_{2}$. The monolayer was then washed vigorously with ice-cold PBS to remove bound but noningested neutrophils. The monolayer of macrophages was lysed with $0.1 \%$ CTAB (hexadecyltrimethyl ammonium bromide) for 15 minutes at $37^{\circ} \mathrm{C}$, then $100 \mu \mathrm{L}$ of lysates was transferred to 96 -well plate in four replicates. Then $100 \mu \mathrm{L}$ of $1 \mathrm{mM}$ substrate for elastase (N-methoxysuccinyl-Ala-Ala-Pro-Val$p$-nitroanilide) solution in Tris buffer $\mathrm{pH} 7.5$ was added. The release of $p$-nitroaniline was monitored at $37^{\circ} \mathrm{C}$ at $405 \mathrm{~nm}$, using a microplate reader (Molecular Devices, Sunnyvale, CA) for 30 minutes. The results were shown as $\mathrm{mOD} / \mathrm{min}$. Macrophages were routinely negative for the elastase activity.

2.7. Measurement of TNF- $\alpha$ Concentration. For the cytokine production assay, hMDMs were cultured in a 24 -well plate in a humidified atmosphere containing $5 \% \mathrm{CO}_{2}$ at $37^{\circ} \mathrm{C}$. In some cultures, fresh, untreated, or treated with heat shock, inhibitors, PI-PLC or mAbs, necrotic or apoptotic neutrophils were added $\left(2.5 \times 10^{6} / 1 \mathrm{~mL} /\right.$ well $)$. Additionally, after $1 \mathrm{hr}$ of coincubation with PMNs, macrophages were stimulated with LPS from Escherichia coli 0127:B8 (Sigma) at a final concentration of $10 \mathrm{ng} / \mathrm{mL}$ or $1 \mu \mathrm{g} / \mathrm{mL}$. After 4 and $24 \mathrm{hrs}$ incubation, supernatants were collected and assayed for TNF- $\alpha$ concentration by ELISA using an OptEIA TNF- $\alpha$ Set (BD Pharmingen), according to the instructions provided with each set of antibodies. The assay was sensitive down to TNF- $\alpha$ concentration of $7 \mathrm{pg} / \mathrm{mL}$. 
2.8. Soluble CD16 ELISA. PMNs were heat shocked as described above. Following incubation done at $37^{\circ} \mathrm{C}, 39^{\circ} \mathrm{C}$, $41^{\circ} \mathrm{C}$, or $43^{\circ} \mathrm{C}$ for 90 minutes, cells were centrifuged at $300 \times \mathrm{g}$ for 7 minutes at RT and supernatants were collected and assayed for soluble CD16. Supernatants from PMA-treated PMNs $\left(10 \mathrm{ng} / \mathrm{mL}\right.$ for 60 minutes at $37^{\circ} \mathrm{C}$ ) were used as positive control. Soluble CD16 were measured by sandwich ELISA. Briefly, wells in microtiter plates (NUNC, Maxisorb) were coated overnight at $4^{\circ} \mathrm{C}$, with $100 \mu \mathrm{L} /$ well of $10 \mu \mathrm{g} / \mathrm{mL}$ mouse IgG1 antihuman CD16 3G8 mAb (BD, Pharmingen). Then plates were washed with washing buffer $(0.05 \%$ Tween20 in PBS) and blocked with $200 \mu \mathrm{L} /$ well of $3 \%$ BSA in PBS for $60 \mathrm{~min}$ at $37^{\circ} \mathrm{C}$. After washing, samples $(100 \mu \mathrm{L} /$ well $)$ were added and incubated for $2 \mathrm{~h}$ at RT with shaking. Plates were washed again, followed by addition of $100 \mu \mathrm{l} /$ well of $0,5 \mu \mathrm{g} / \mathrm{mL}$ FITC-conjugated mouse IgG antihuman CD16 DJ130c mAb (Dako), and incubated for $1 \mathrm{~h}$ at RT. After washing, plates were incubated for $1 \mathrm{~h}$ at RT with $100 \mu \mathrm{L} /$ well of 1:2000 dilution of sheep IgG (Fab fragment) anti-FITC conjugated with HRP (Roche). Following last washing step, enzymatic reaction was developed with $\mathrm{TMB} / \mathrm{H}_{2} \mathrm{O}_{2}$ for 15 min at RT and then stopped with $\mathrm{H}_{2} \mathrm{SO}_{4}$. Absorbance was read at $450 \mathrm{~nm}$ with correction at $630 \mathrm{~nm}$ using a microplate spectrophotometer (Infinite M200, TECAN).

2.9. Statistical Analyses. All experiments were performed in triplicate, unless otherwise stated. The data are presented as means $( \pm \mathrm{SD})$. All statistics were calculated using Origin 8.1 (OriginLab Corporation, Northampton, MA, USA), and calculated $P$ values are shown in the figures. Statistical significance was asset at 5\% and calculated using Student's $t$-test.

\section{Results}

3.1. Heat-Shocked Neutrophils Are Functional and Do Not Demonstrate Features of Cell Death. A distinctive early feature of cell apoptosis is the externalization of PS into the outer leaflet of the plasma membrane [32], which constitutes an "eat-me" signal for neighboring phagocytes. Therefore, we have carefully studied the PS exposure on fresh and heat-shocked neutrophils. The level of PS on the neutrophils surface was evaluated by staining with FITCconjugated Annexin V followed by a flow cytometry analysis. The $90 \mathrm{~min}$ exposure of healthy neutrophils to HS resulted in only marginal binding of annexin $\mathrm{V}$ and permeability to propidium iodide (PI) in about $4 \%$ of cells (Figures $1(\mathrm{a})$ and $1(\mathrm{~b})$ ). In addition, heat shock did not have any significant effect on the surface expression of Annexin I and Annexin II, molecules known to be involved in apoptotic cells recognition (Figure 1(b)). Neutrophil exposure to heat shock $\left(39,41\right.$, or $\left.43^{\circ} \mathrm{C}\right)$ did not stimulate these cells clearance by resting human monocyte-derived macrophages (hMDM) (Figure 1(c)). The measured phagocytosis did not statistically differ from that obtained for freshly isolated cells. Temperature $45^{\circ} \mathrm{C}$ resulted in increased engulfment but still much lower than that observed for spontaneously apoptotic neutrophils (not shown). Interestingly, additional (24 hrs) incubation of the heat shocked (HS) neutrophils in standard culture conditions resulted in their efficient engulfment by hMDMs (Figure 1(c)).

To test the possibility that heat shock may affect later stages of spontaneously occurring apoptosis, we have compared the integrity of DNA derived from HS-treated and untreated neutrophils cultivated for $24 \mathrm{hrs}$. Surprisingly, the DNA electrophoretical analysis demonstrated considerable, temperature-dependent inhibition of spontaneous, apoptotic DNA fragmentation in HS-treated neutrophils (Figure 1(d)).

Importantly, with exception of the highest temperature $\left(45^{\circ} \mathrm{C}\right)$, heat shock did not permeabilize neutrophils for trypan blue uptake (data not shown). Accordingly heat shocked (HS) neutrophils $\left(39,41\right.$, or $\left.43^{\circ} \mathrm{C}\right)$ did not release significant amount of $\mathrm{LDH}$ into the media. Also, no release of HNE was observed. However, both LDH and HNE were found in media at the substantial levels when neutrophils were exposed to $\mathrm{HS}$ at $45^{\circ} \mathrm{C}$ (Figure $1(\mathrm{e})$ ). This indicates that only at temperatures above $43^{\circ} \mathrm{C}$ the cell membrane integrity was compromised.

Morphological analysis by phase contrast microscopy and TEM did not show any remarkable difference between freshly isolated and $\mathrm{HS}\left(41^{\circ} \mathrm{C}\right)$ neutrophils (data not shown).

Based on these findings, we have selected the heat shock temperatures $39^{\circ} \mathrm{C}$ and $41^{\circ} \mathrm{C}$ for follow-up experiments since such treatment did not affect the neutrophils viability, phenotype, nor induced their phagocytosis by macrophages.

3.2. Recognition of Heat-Shocked Neutrophils Is Nonphlogistic. Several reports have indicated that the uptake of apoptotic cells changes the macrophage phenotype from pro- to anti-inflammatory (extensively reviewed by Savill et al. [7]). Therefore, we tested the proinflammatory response of hMDM, measured as TNF- $\alpha$ release into the media, to the contact with HS-treated neutrophils. To our surprise, in the stark contrast to necrotic neutrophils, which stimulated the massive proinflammatory response comparable to that elicited by LPS, the coculturing of macrophages with the HS cells exerted no effect on the TNF- $\alpha$ secretion (Figure 2(a)). No release of IL-10, the major anti-inflammatory cytokine, has been detected (data not shown). As a matter of fact, the TNF- $\alpha$ secretion by macrophages exposed to HS neutrophils was significantly lower than that observed in the cocultures of hMDM with fresh neutrophils and only slightly higher than that in cocultures with spontaneously apoptotic neutrophils. Similarly, the HS neutrophils inhibited the LPSinduced TNF- $\alpha$ secretion by hMDMs (Figure 2(b)). The anti-inflammatory effect was much more pronounced when hMDMs were stimulated with LPS at low concentration (10 ng/mL).

\subsection{Surface Expression of Major "Don't Eat Me" Signal CD31 (PECAM) Is Modulated by Heat Shock. Response of macrophages to apoptotic PMNs includes recognition of modified antiphagocytic molecules expressed to protect fully functional cells against unscheduled clearance. Two major "don't eat me" signals-CD31 and CD47-have been most studied $[33,34]$. Consequently, we have measured binding of}




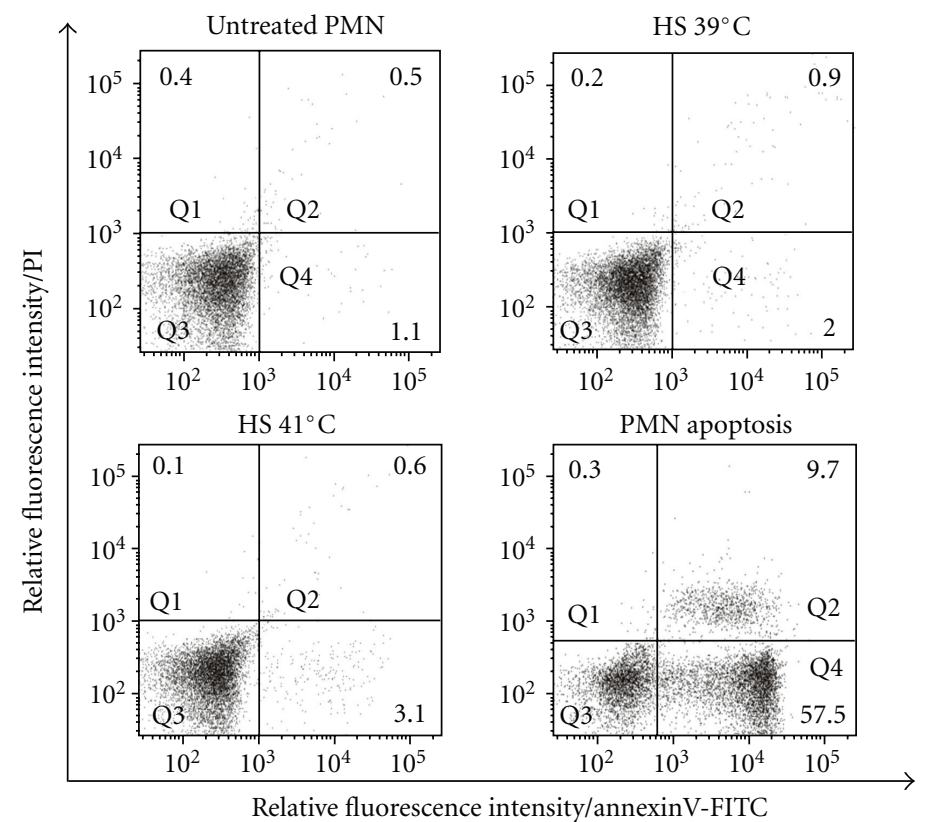

(a)
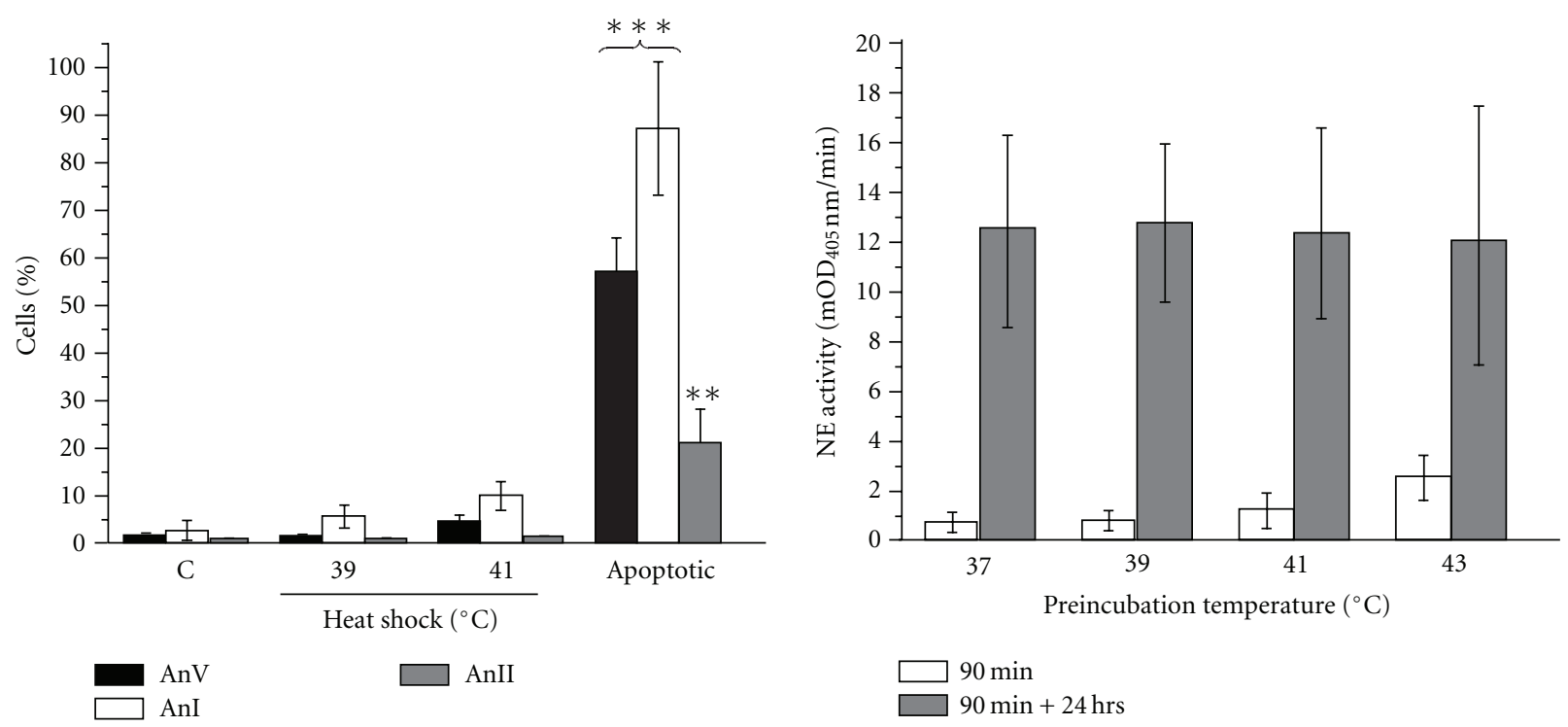

(b)

(c)

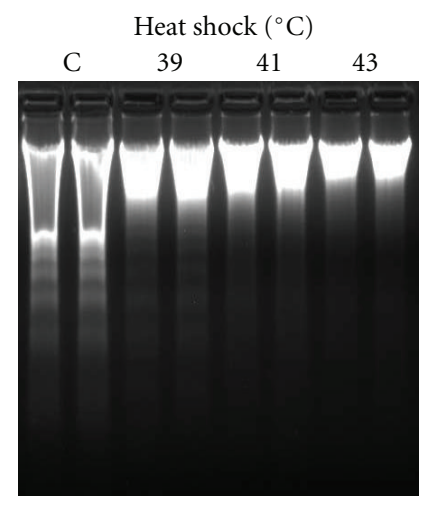

(d)

FIgURe 1: Continued. 


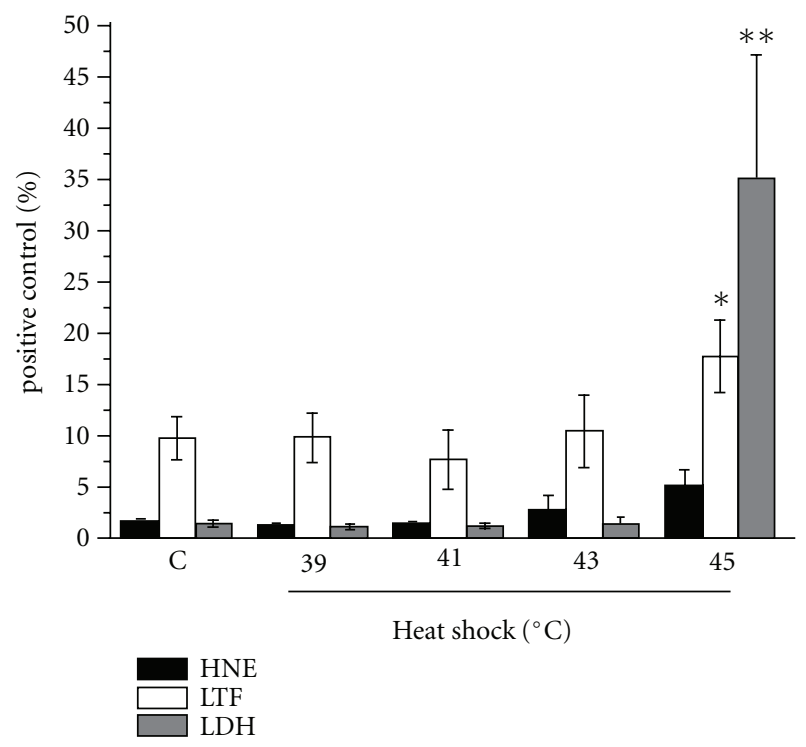

(e)

FIGURE 1: Delayed apoptosis in heat-shocked PMNs neutrophils. (a) Annexin V and propidium iodide staining of control, heat shocked $\left(39^{\circ} \mathrm{C}\right.$ or $41^{\circ} \mathrm{C}, 90 \mathrm{~min}$ ) or apoptotic neutrophils. The percentage of cells in each subpopulation is shown in dot plots. Results of representative experiment of three performed are presented. (b) Expression of PS, annexin I and II on control, heat-shocked, or apoptotic neutrophils. (c) Effect of HS on the phagocytosis of neutrophils by hMDM. Phagocytosis of fresh, healthy neutrophils, preincubated at indicated temperatures $\left(37-43^{\circ} \mathrm{C}, 90 \mathrm{~min}\right)$ measured immediately following preincubation (open bars) or after additional 24 hrs culture in standard conditions (gray bars). Neutrophils were added to macrophages at $2.5 \times 10^{6}$ cell/well of 24 -well plate in medium with $10 \%$ human serum and incubated for $2 \mathrm{hrs}$ at $37^{\circ} \mathrm{C}$. Noningested neutrophils were removed by intensive washing of the hMDM monolayer. The cells were solubilized with detergent and the neutrophil elastase activity was measured in lysates as described in materials and methods. The intensity of phagocytosis is expressed as $\mathrm{mOD} / \mathrm{min}$ of the substrate turnover catalyzed by neutrophil-derived elastase. (d) Heat shock inhibits DNA fragmentation in neutrophils. Freshly isolated neutrophils (control) or the cells treated for $90 \mathrm{~min}$ with heat shock were allowed to underwent spontaneous apoptosis for $24 \mathrm{hrs}$ before DNA was isolated and subjected to electrophoresis. Results of a representative experiment out of three are presented in duplicates. (e) Preservation of the cell membrane integrity in heat-shocked neutrophils. The release of LTF, HNE, and LDH to the medium was measured following neutrophils treatment with heat shock for $90 \mathrm{~min}$. The LTF, HNE, and LDH concentration in the culture medium of necrotic (sonicated) neutrophils was set as the positive control $(100 \%)$. Data presented are mean $\left( \pm\right.$ SD). ${ }^{*} P<.05,{ }^{* *} P<.01$, and ${ }^{* * *} P<.001$, relative to controls, $\mathrm{C}$.

CD31- and CD47-specific mAbs to HS neutrophils. Results presented in Figure 3 clearly demonstrate a decrease in expression of CD31 which was apparent in fluorescence intensity and distribution. Interestingly, a characteristic "CD31-low" subpopulation appeared transiently on HS cells immediately following HS. No change in CD47 expression was seen on HS neutrophils (not shown). As the CD31 and CD47 expression is sharply downregulated during apoptosis, the untypical expression of these molecules on the HStreated cells reiterates their nonapoptotic phenotype.

3.4. Surface Expression of Fcy Receptor III (CD16) Is Permanently Reduced by Heat Shock. As CD16 was the first cell membrane receptor whose reduction in surface expression was described in cells undergoing apoptosis [35], we were interested in its expression on HS PMNs. Surprisingly, we found rapid, temperature-dependent decrease in surface expression of Fc $\gamma$ RIII. As shown in Figure 4 and Table 1, $39^{\circ} \mathrm{C}$ and $41^{\circ} \mathrm{C}$ HS was sufficient to reduce the CD16 level to about 70 and $60 \%$, respectively, and incubation of PMN in $43^{\circ} \mathrm{C}$ caused reduction of CD16 density to about $30 \%$ of the control cells. In contrast to the spontaneously apoptotic PMNs where the CD16-low population had been described, the decrease of CD16 on HS PMNs concerned the entire population. Moreover, the HS-induced CD16 decrease was only partially inhibited by EDTA or O-phenanthroline both known as general metalloproteinase inhibitors (not shown).

3.5. Shedding of CD16 Is Temperature Independent. Assuming proteolytic shedding as the major factor contributing to the observed downregulation of surface CD16, we expected accumulation of soluble CD16 (sCD16) in the supernates of HS neutrophils. The sandwich ELISA based on the most popular clone 3G8 as capture antibody and the clone Dj130c as detection antibody was used. PMA-induced shedding of CD16 served as a positive control and we noticed strongly increased (more then two times) release of sCD16. Cytochalasin D demonstrated similar activity (not shown). Surprisingly, as shown in Figure 5, the amount of sCD16 generated in supernates was shock temperature independent. Only at $43^{\circ} \mathrm{C}$, we observed minor (about 10\%) increase of sCD16 in supernates. Consequently, we assumed that 


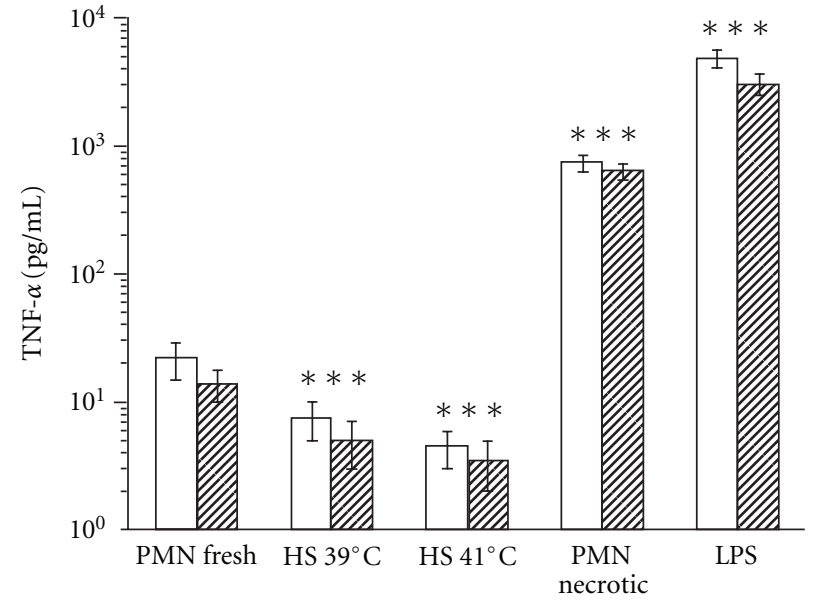

$4 \mathrm{hrs}$

$24 \mathrm{hrs}$

(a)

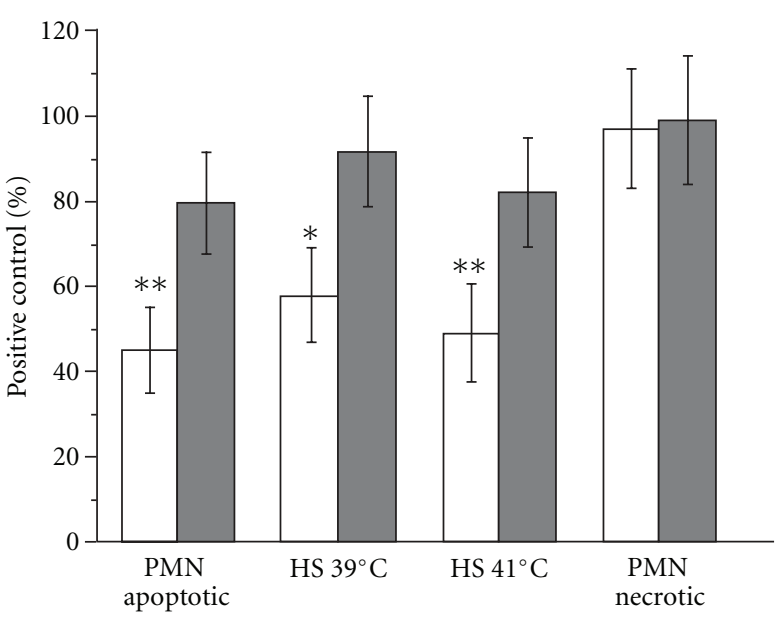

(b)

FIgURE 2: Recognition of heat-shocked neutrophils is nonphlogistic. (a) hMDMs were cocultured for 4 or 24 hrs with fresh, heat-shocked (39 or $41^{\circ} \mathrm{C}, 90 \mathrm{~min}$ ), or necrotic neutrophils or stimulated with $10 \mathrm{ng} / \mathrm{mL}$ LPS (E. coli). TNF- $\alpha$ was subsequently measured in cell-free culture supernatants. Data presented are mean $( \pm \mathrm{SD}) .{ }^{* * *} P<.001$, relative to control, PMN fresh. (b) hMDMs were cocultured for 1 hr with apoptotic, heat-shocked $\left(39\right.$ or $41^{\circ} \mathrm{C}, 90 \mathrm{~min}$ ), or necrotic neutrophils. The cocultures were then stimulated for $4 \mathrm{hrs}$ with $10 \mathrm{ng} / \mathrm{ml}$ or $1 \mu \mathrm{g} / \mathrm{ml}$ LPS (E. coli). TNF- $\alpha$ was subsequently measured in cell-free culture supernatants. Results are expressed as percent (mean \pm SD) of positive control that is hMDMs stimulated with LPS. ${ }^{*} P<.05$, ${ }^{* *} P<.01$, relative to positive control. PMNs incubated in standard culture conditions up to $120 \mathrm{~min}$ had the same effect as freshly isolated cells (data not shown).

TABLE 1: Surface expression of Fc $y$ receptor III (CD16) is reduced by heat shock. Neutrophils incubated for $90 \mathrm{~min}$. at indicated temperatures were stained with PE-conjugated antihuman CD16 $\mathrm{mAb}$ and analyzed by flow cytometry. The Mean Fluorescence Intensity (MFI) values were calculated against the signal from isotype control and they represent neutrophils positive for CD16. Results (mean \pm standard deviation) from four experiments are presented.

\begin{tabular}{lc}
\hline Incubation temperature $\left({ }^{\circ} \mathrm{C}\right)$ & $\begin{array}{c}\text { Mean Fluorescence Intensity } \\
\mathrm{X}_{n=4} \pm \text { S.D. }\end{array}$ \\
\hline 37 & $21940 \pm 3507$ \\
39 & $17070 \pm 2871$ \\
41 & $14287 \pm 2191$ \\
43 & $4942 \pm 790$ \\
\hline
\end{tabular}

proteolytic shedding was not the only reason of decreased expression of CD16 following heat shock.

3.6. Inhibition of Surface CD16 Expression by Heat Shock Is Enhanced by HSP90 Inhibitors, Geldanamycin, or Radicicol. It has been previously shown that the expression level of CD16 by neutrophils is the net result of surface shedding and translocation from secretory vesicles containing CD16 [36]. We therefore investigated surface CD16 expression by PMN treated with HSP90 inhibitors. As shown in Figure 6, inhibition of surface expression of CD16 on HS neutrophils was much stronger in the presence of HSP90 inhibitors. They did not modify significantly CD 16 expression on control cells but when PMNs were shocked in the presence of geldanamycin $(10 \mu \mathrm{M})$ or radicicol $(10 \mu \mathrm{M})$ the expression of surface CD16 was reduced by at least $50 \%$ of untreated control. Viability of HS PMNs was still preserved (not shown).

3.7. The Anti-Inflammatory Effect of HS Neutrophils Is Enhanced by HSP90 Inhibitors, Geldanamycin or Radicicol and Involves Low CD16 Expression. The observed cooperation between heat shock and HSP90 inhibitors prompted us to test the response of hMDM to contact with such treated neutrophils. Data presented in Figure 7(a) clearly show that anti-inflammatory effect of these cells was enhanced. Recognition of PMN treated with radicicol or geldanamycin during heat shock drastically decreased TNF $\alpha$ secretion by LPS-stimulated macrophages. Moreover, PMN treated with PI-PLC, in which CD16 expression was reduced to about $50 \%$, also suppressed LPS-induced TNF- $\alpha$ release to the level exerted by recognition of heat shocked cells.

Treatment of PMNs with the small molecule Rac inhibitor NSC23766 which is known to inhibit primary granule exocytosis [37] also resulted in significant inhibition of CD16 expression and proportional inhibition of TNF- $\alpha$ production.

To specifically address the role of CD16 in the observed activity of geldanamycin and radicicol, we used blocking antibodies against different CD16 epitopes (Figure 7(b)). Such approach has been proved effective in blocking 


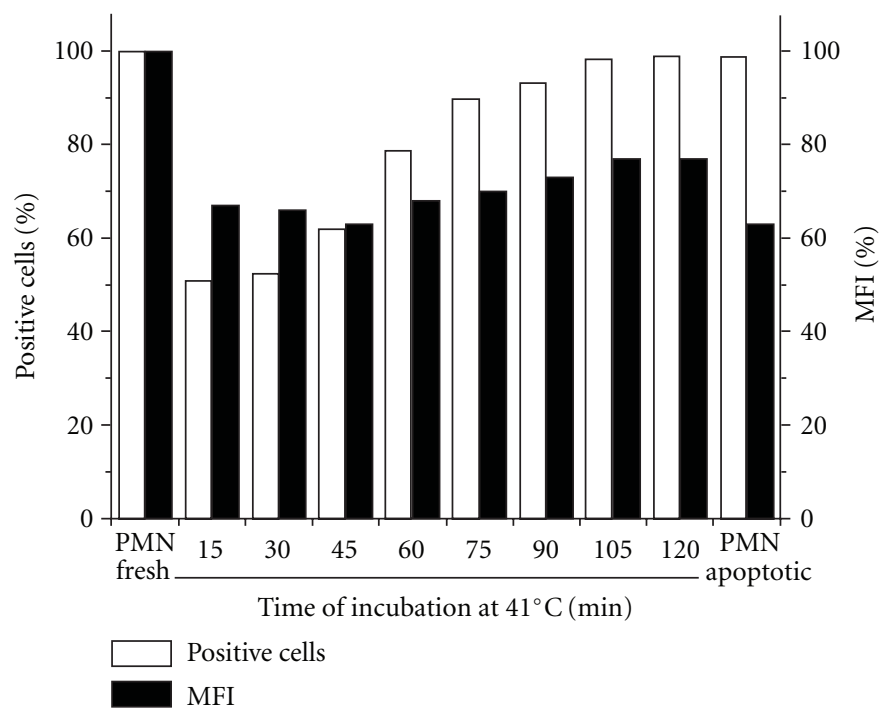

(a)
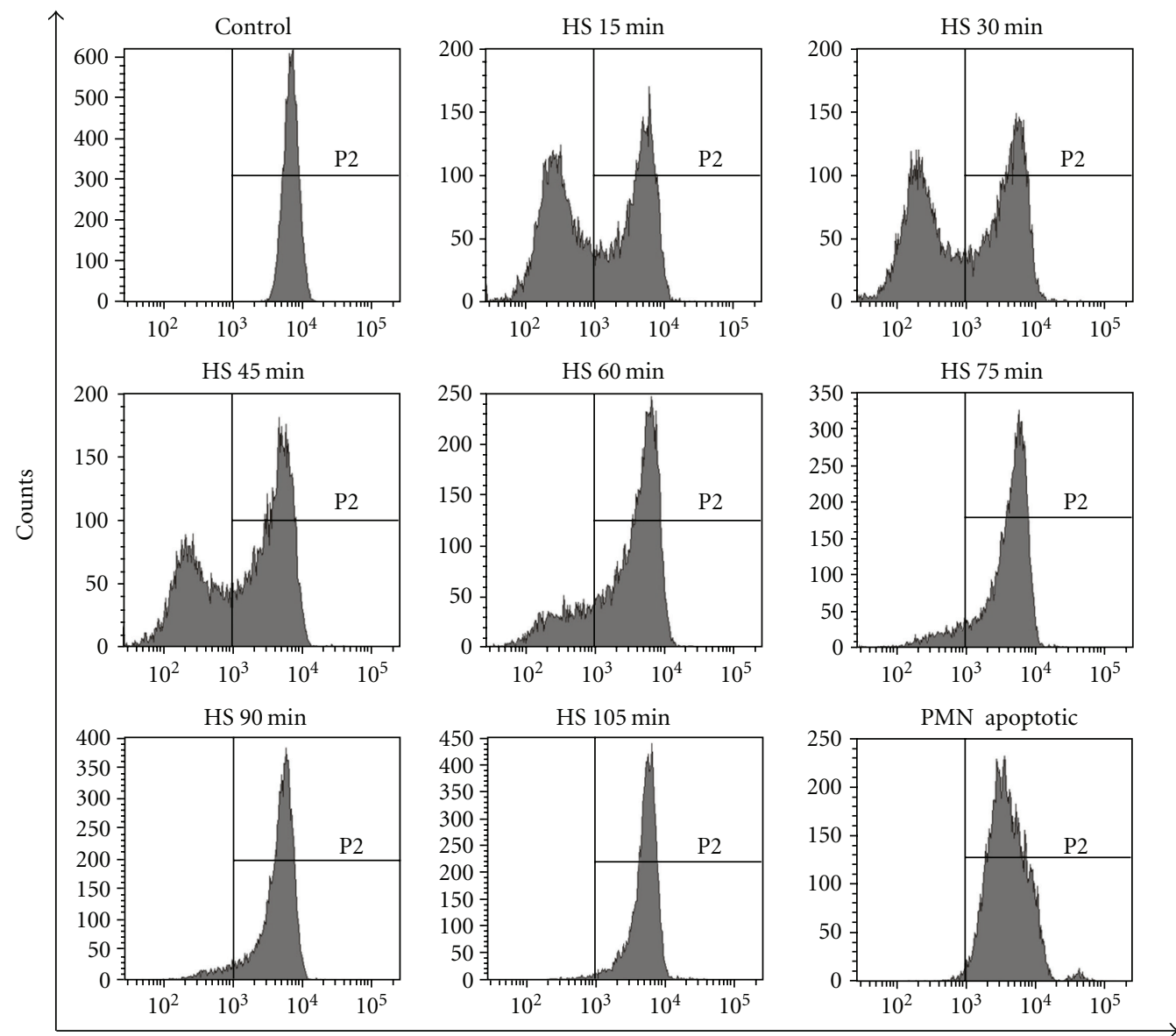

Relative fluorescence intensity/CD31-PE

(b)

FIGURE 3: Expression of CD31 is modulated on heat-shocked neutrophils. Fresh, apoptotic, and HS neutrophils (incubated at $41^{\circ} \mathrm{C}$ for indicated time) were stained with PE-conjugated antihuman CD31 mAb and analyzed by flow cytometry. (a) Open bars represent the percent of CD31-positive cells; black bars represent mean fluorescent intensity (MFI) expressed as percent of MFI measured for control, fresh PMNs. (b) Flow cytometry histograms from the same experiment are presented. The histogram markers were set based on the signal from isotype control and they designated section of the histogram representing neutrophils positive for CD31. Results of a representative experiment of three performed are presented. PMNs incubated in standard culture conditions up to 120 min expressed CD31 with the same intensity as freshly isolated cells (Positive cells, $98.17 \pm 3.09 \%$; MFI, $6839 \pm 640.88$ ). 


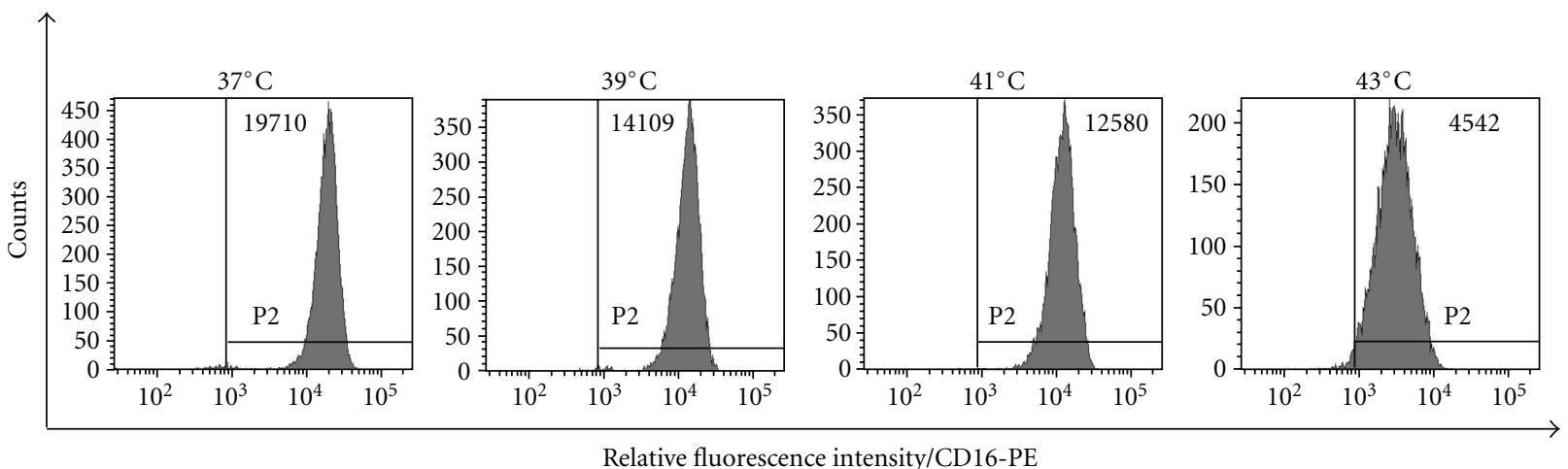

FIgURE 4: Surface expression of Fc $\gamma$ receptor III (CD16) is reduced by heat shock. Neutrophils incubated for 90 min, at indicated temperatures were stained with PE-conjugated antihuman CD16 mAb and analyzed by flow cytometry. The histogram markers were set based on the signal from isotype control (Mouse IgG1-PE clone MOPC-21), and they designated section of the histogram representing neutrophils positive for CD16. The values of MFI are given in histograms. Results of a representative experiment of four performed are presented (complete data in Table 1).

neutrophil phagocytosis [38]. For all four mAbs, statistically significant inhibition of TNF- $\alpha$ production by LPSstimulated macrophages has been observed although the visible differences between mAbs suggested the importance of particular epitopes.

Taken together, these data indicate that diminished expression of or hampered access to neutrophils' CD16 is involved in their anti-inflammatory recognition by macrophages.

\section{Discussion}

Here we present evidence for an alternative and potentially injury-limiting neutrophil recognition mechanism, whereby heat-shocked neutrophils are not phagocytosed by macrophages. For the first time, we describe significant reduction of expression of neutrophil CD16 on viable, nonapoptotic neutrophils in conditions which inhibited the spontaneous apoptosis. We also demonstrate an intimate association of reduced neutrophil CD16 with their nonphlogistic recognition by macrophages. Unlike apoptotic neutrophils, the HS cells preserve membrane assymetry typical for viable, fully functional PMNs; moreover, the expression of selected cell-surface molecules known to be involved in apoptotic recognition: annexin I and II, CD31, and CD47 was not changed.

Because neutrophil CD16 is known to be actively shed by yet unknown membrane metalloproteinase [39, 40], we wondered if altered proteolysis processing during heat stress accounted for reduced expression of CD16. Indeed, reduction in expression of CD16 could be partially prevented by addition of general metalloproteinase inhibitors (Ophenanthroline or EDTA) to culture medium. However, unchanged concentration of sCD16 in supernates from HS cells would argue against a generalized up-regulation of CD16-specific proteolytic activity as a result of heat shock. HS-induced reduction in CD16 expression appears notable in that it represents loss of the majority of surface receptors, as opposed to a gradual reduction in surface expression. In contrast, when neutrophils are activated with PMA (typical secretagogue), membrane expression of CD16 is transiently increased in spite of extensive shedding, levels of surface expression of CD16 reflecting a balance between receptor shedding and mobilization from intracellular stores [36]. The appearance of CD16 low-expressing PMN population during HS might be accounted for by temporal differences in downmodulation by heat of the processes of receptor mobilization and shedding. To further exploit the mechanism of the observed phenomenon, we applied two highly specific inhibitors of HSP90-radicicol and geldanamycin [40]. HSP90, a molecular chaperone involved in heat shock and cytoprotection, was also found to be a constitutive component of multimeric receptor complexes comprising Toll-like receptors, chemokine receptors, and integrins situated together within membrane microdomains $[41,42]$. CD16 was also found to participate in the same receptor complexes [43]. In heat stress conditions, most preexisting HSP90 is redirected ad hoc to protect protein conformation and its intracellular availability dramatically decreases. Although the role of HSP90 in the signalling complexes is not clear we assumed that HSP90 is involved in chaperoning CD16 during its transport and externalization in lipid rafts. Continued shedding of surface CD16 without replenishment from intracellular stores in the presence of HSP90 inhibitors may give rise to CD16 extremely low expressing neutrophils. As demonstrated, combined effect of heat stress and HSP90 inhibition effectively hampered the surface expression of CD16. Treatment with small molecule Rac inhibitor NSC23766 which is known to inhibit primary granule exocytosis [37] resulted in significant reduction in expression of CD16 (Figure 7(a)) which was enhanced by heat shock (not shown), indicating that inhibition by heat of the dynamic component of CD16 redistribution to the cell surface plays an essential role in the observed effect. Additional studies are underway in this laboratory to address the underlying mechanism.

In stark contrast to the original finding by Dransfeld and colleagues [35], we have been unable to correlate the reduction in CD16 expression on HS neutrophils with their 


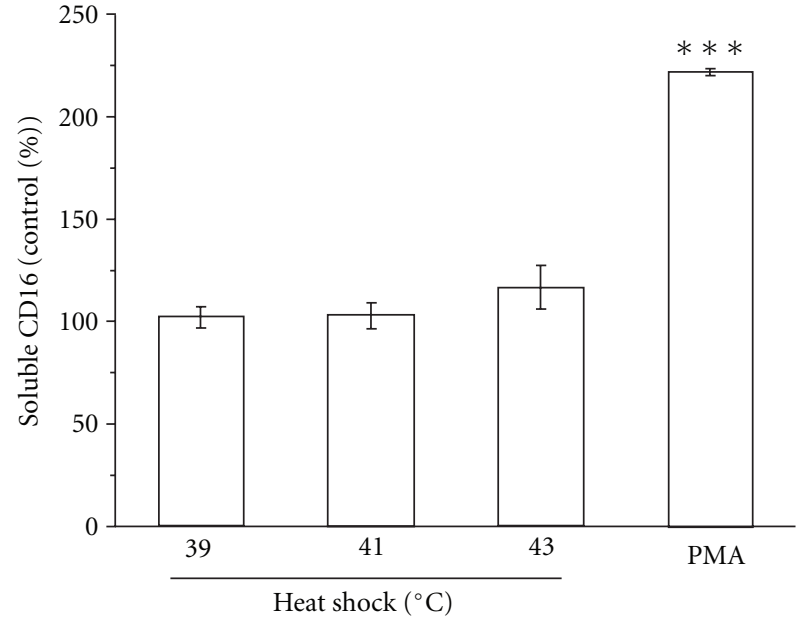

FIgURE 5: Shedding of CD16 is temperature independent. Soluble CD16 was assayed in supernates taken from neutrophils incubated for $90 \mathrm{~min}$ at indicated temperatures or treated with PMA $(10 \mathrm{ng} / \mathrm{mL})$ for $60 \mathrm{~min}$. The amount of soluble CD16 was determined by sandwich ELISA. Measured OD were recalculated, and results are expressed as percent of control (supernates from $\mathrm{PMN}$ incubated at $\left.37^{\circ} \mathrm{C}\right)$. Data presented are mean $( \pm \mathrm{SD})$. ${ }^{* * *} \mathrm{P}<$ .001 , relative to control.

apoptosis. Firstly, HS treatment evidently slowed down the spontaneous PMN apoptosis which is best visible in DNA laddering analysis and may have some basis in the cell deactivation described by others $[25,28]$. Secondly, when preincubation with the HSP90 inhibitors was combined with $\mathrm{HS}$ at $43^{\circ} \mathrm{C}$ (a treatment which reduced CD16 expression to about $20 \%$ of the control value), we observed total block of the neutrophil DNA fragmentation. Interestingly, our data strongly suggest inhibition of executive phase of apoptosis in HS-treated cells, thus raising interest in the further fate of HS neutrophils.

In terms of function, we were mostly interested in recognition of HS neutrophils by macrophages. Using the elastase assay [31], we were able to quantitatively analyse the engulfment of HS-treated neutrophils by hMDMs. Results presented in Figure 1(c) allowed us to conclude that HS, despite of transient modulation of CD31, a major "don't eat me" signal, did not generate a recognition signal on the neutrophils' surface sufficient for their engulfment. Unexpectedly, the HS-treated neutrophils did not stimulate macrophages to produce TNF- $\alpha$, contrary, they efficiently inhibited LPS-induced TNF- $\alpha$ production. Direct comparison with necrotic neutrophils demonstrated that HS-treated cells initiated release of only small amounts of TNF- $\alpha$, less than observed in the case of fresh neutrophils. This was surprising for two reasons: first, as described above, the antiinflammatory recognition of HS neutrophils by macrophages occurred without their phagocytic removal-a typical consequence of recognition of dysfunctional cells; second, the HS neutrophils did not expose PS, which usually implies anti-inflammatory consequences of their recognition. The inability of HS-treated neutrophils to initiate TNF- $\alpha$ release stays in agreement with intracellular containment of LTF,

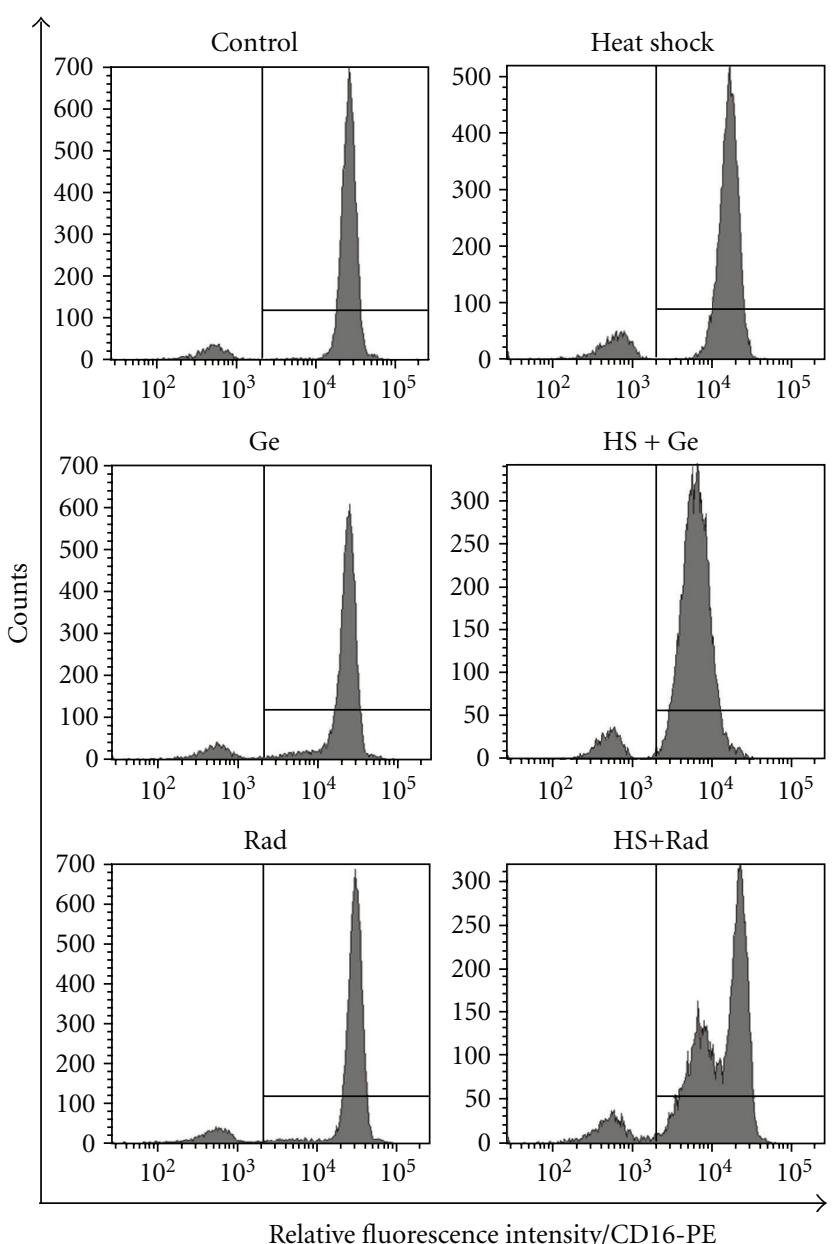

FIGURE 6: Geldanamycin and radicicol enhance the effect of HS on surface expression of CD16. Neutrophils were incubated initially for $30 \mathrm{~min}$ at $37^{\circ} \mathrm{C}$ with or without inhibitors of HSP90: geldanamycin (Ge) or radicicol ( $\mathrm{Rad}$ ) and then for additional $90 \mathrm{~min}$ at $37^{\circ} \mathrm{C}$ (control) or $41^{\circ} \mathrm{C}$ (heat shock). Finally, cells were stained with PEconjugated antihuman CD16 mAb and analyzed by flow cytometry. The histogram markers were set based on the signal from isotype control (Mouse IgG1-PE clone MOPC-21) and they designated section of the histogram representing neutrophils positive for CD16. Results of a representative experiment of three performed are presented.

HNE, and LDH by the cells and strongly argues for the absence of necrotic cell death.

Significantly, the threshold temperature at which some components of spontaneous apoptosis is already inhibited seems to be very low (Figure 1(d)). On the other hand, increasing $\mathrm{HS}$ temperature to $45^{\circ} \mathrm{C}$ resulted in rapid loss of viability and membrane integrity typical for necrotic cells.

The anti-inflammatory effect of HS PMNs is apparently not mediated by the sCD16 shed from the neutrophils surface. For one thing, PMNs were contacted with macrophages after disposal of incubation medium, and for another we have shown that the amount of sCD16 did not change with HS temperature while the anti-inflammatory activity of HS PMNs increased. 


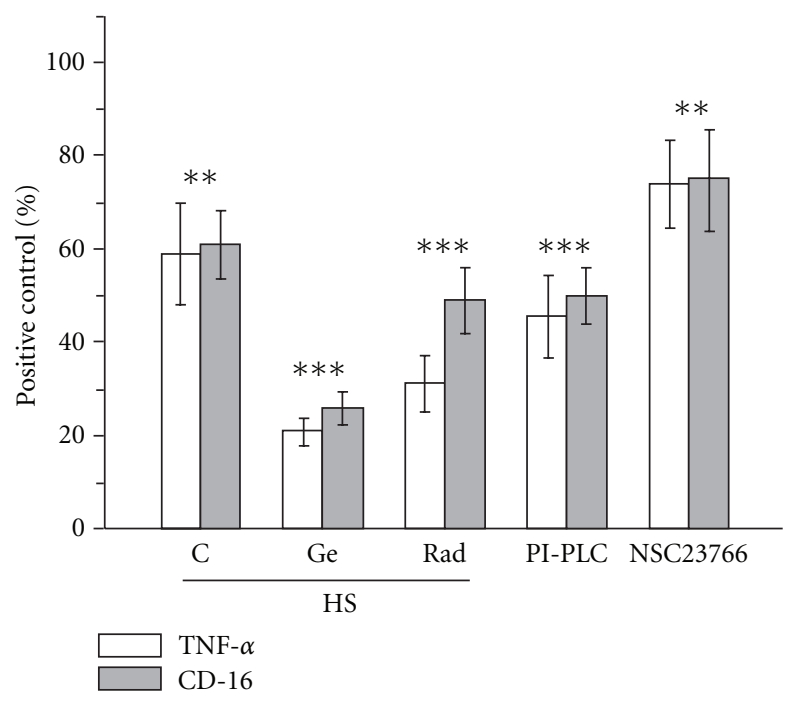

(a)

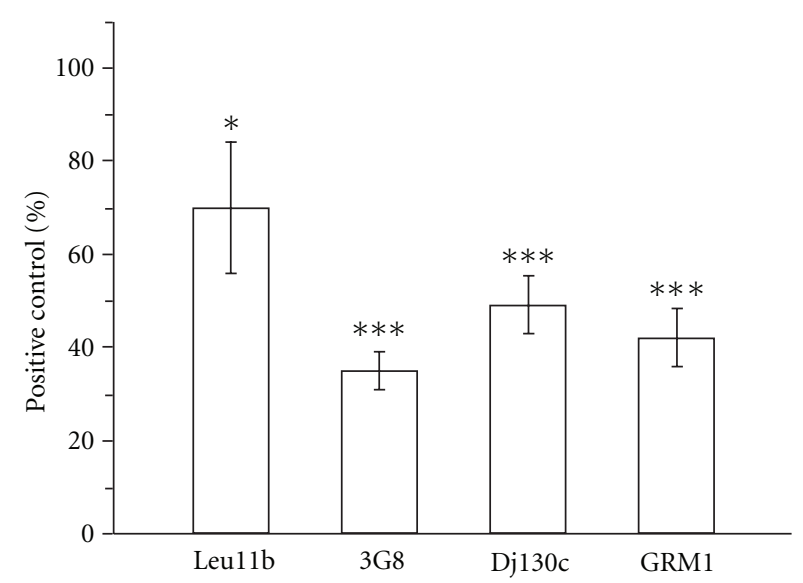

(b)

FIGURE 7: Geldanamycin and radicicol enhance the anti-inflammatory effect of HS neutrophils which is associated with decrease of CD16 expression. (a) Neutrophils were incubated initially for $30 \mathrm{~min}$ at $37^{\circ} \mathrm{C}$ with or without (C) inhibitors of HSP90: geldanamycin (Ge) or radicicol (Rad) and then for additional $90 \mathrm{~min}$ at $41^{\circ} \mathrm{C}(\mathrm{HS})$. For enzymatic removal of surface CD16 PMNs were incubated with PI-PLC $(0.5 \mathrm{IU} / \mathrm{mL})$ for $45 \mathrm{~min}$ at $37^{\circ} \mathrm{C}$ in culture medium without serum. The enzymatic reaction was stopped by serum addition. For inhibition of spontaneous exocytosis PMNs were incubated with Rac inhibitor NSC23766 (50 $\mu \mathrm{M})$ for $15 \mathrm{~min}$ at $37^{\circ} \mathrm{C}$ in culture medium. Finally, cells were centrifuged, resuspended in fresh culture medium and added to macrophages. Following $1 \mathrm{hr}$ of co-incubation cytokine production was stimulated with $10 \mathrm{ng} / \mathrm{mL}$ LPS (E. coli, 0127:B8) for 4 hrs. TNF- $\alpha$ was subsequently measured in cell-free culture supernatants (open bars). Prior to addition to macrophages an aliquot of neutrophils was subjected to flow cytometric (MFI) measurement of CD16 expression (gray bars). (b) The anti-inflammatory effect of neutrophils was induced by preincubation of PMNs with CD16-specific antibodies (clones Leu11b, 3G8, Dj130c and GRM1) for $15 \mathrm{~min}$ at $20^{\circ} \mathrm{C}$ in culture medium. Following the preincubation neutrophils were resuspended in fresh culture medium and added to macrophages. Results (TNF- $\alpha$ ) are expressed as percent (mean \pm SD) of positive control that is hMDMs stimulated with LPS. Results (CD16) are expressed as percent (mean $\pm \mathrm{SD}$ ) of positive control that is freshly isolated neutrophils. ${ }^{*} P<.01,{ }^{* * *} P<.001$, relative to positive control.

The postulated novel regulatory role of HS PMNs is unique in three major aspects: firstly, unlike apoptotic PMNs the HS cells do not generate sCD16 (Figure 5); secondly, their apoptotic programme is slowed down (Figure 1(d)), and they are not engulfed by macrophages (Figure 1(c)); finally, modulation of surface CD16 correlated with the ability of PMNs to reduce macrophage responses to LPS, and the blocking activity of four anti-CD16 mAb clones (Figure 7(b)) strongly suggests a causative relationship. Still, it is unclear how macrophages recognize lower expression of PMN CD16 and how this would provide an antiinflammatory stimulus without typical signals of apoptosis (PS-externalization, shedding of CD31 and CD47). Interestingly, the $\mathrm{CD} 16^{-}$subpopulation of human peripheral blood monocytes is known to produce lesser (5-10 times) amounts of TNF- $\alpha$ than the CD16 $6^{+}$cells in response to LPS, zymosan, or S.aureus [44].

Proteolytic shedding of CD16 is a part of S.aureus pathogenicity and leads to anti-inflammatory recognition and engulfment of PMNs by hMDMs [45, 46]. However, the presence of IgG efficiently protected the cells against this challenge pointing at $\mathrm{CD} 16-\mathrm{Fc}$-fragment complex as a critical factor stabilizing also CD11b, most probably through lateral interactions [47]. In contrast to S.aureus proteases, heat shock and HSP90 inhibitors reduced the expression of CD16 in the presence of IgG since most experiments described here were performed in the presence of autologous serum. The difference may result from differential location of the cleavage site used by bacterial and cellular proteases. Nevertheless, we also observed some decrease in surface expression of CD11b as a result of heat shock (not shown). It is therefore possible that downmodulation of neutrophil CD16 may also affect the function of CD11b. Interestingly, phagocytic activity of the heat-shocked neutrophils was preserved and only marginally decreased against opsonised S.aureus (not shown). This concurres with our previous data concerning heat-shocked monocytes whose phagocytosis of S.aureus was even increased [30].

Although there are few data on PMNs subpopulations in peripheral blood of healthy donors which would differ in expression of CD31 or CD16, in some cases the HStreatment resulted in clearly bimodal fluorescence histograms (Figures $3(\mathrm{~b})$ and $6 \mathrm{HS}+\mathrm{Rad})$. We speculate that the observed subpopulations differed in their basal level of activation of signal transduction pathways. Preactivated ("primed") neutrophil subpopulation has been described several times, and it may appear in blood of healthy donors [48, 49]. The "primed" cells may have lesser capability to manage the subsequent heat stress (especially in the presence of HSP90 inhibitors) as active signal transduction pathways engage 
most of the cellular HSP90 pool. Consequently, the "primed" subpopulation is more likely to destabilize the membrane receptor complexes in the described stressful conditions. This effect has been observed also when heat shock was combined with higher concentration of geldanamycin (data not shown).

Although indirectly, the mechanism described here may importantly contribute to the homeostasis during short fever episodes known under common name "intermittent fever" when elevated temperature is present only for some hours of the day and becomes normal for remaining hours. It seems that HS neutrophils, which are not removed by resident macrophages and retain at least some of their vital functions, may substitute for the regulatory role of the apoptotic neutrophils. Such scenario may cast some light on the protective role of fever, pointing at the fever peak temperatures and duration as critical factors of homeostasis. A paradox of fever pathogenicity, already mentioned above, is that the fraction of apoptotic neutrophils found in the patients' circulation is very low-not different from that of healthy individuals [26, 27] yet apoptosis of neutrophils in prolonged hyperthermia is clearly accelerated $[24,50]$. In light of our results, it may be explained, by the fact that shortly heat-stressed neutrophils do not qualify as apoptotic by any criterion, that they would rather fall into a class of deactivated or "deprimed" cells, which is in accordance with other reports $[25,28]$. Inhibition of apoptotic DNA laddering by HS is of critical significance when diagnostics of clinical samples is based on DNA or nuclear fragmentation-TUNEL, comet assay, or Giemsastained microscopic preparations.

The influence of elevated temperatures on the viability of neutrophils has been explored in many lines using different, if not contradictory approaches. This resulted in discordant data which are very difficult to summarize in a coherent picture. It should be stressed that the general concept of our work was different from those exploited recently by groups studying heat shock or hyperthermia. Inspired by the original study by Dransfield and colleagues [35], we performed experiments in the presence of autologous serum, thus providing native $\operatorname{IgG}$ species, as we believed it served a critical role in stabilizing CD11b-CD16 membrane complexes. We also used short time of effective neutrophils heat treatment ( $90 \mathrm{~min})$. In our opinion, such approach may reflect the short febrile attacks with high-peak temperatures. Consequently, our results differ from the data obtained by other groups in several points: firstly, we have demonstrated a significant inhibition of apoptotic DNA "laddering" by heat shock which has not been reported earlier; secondly, neutrophils acquired some anti-inflammatory properties immediately following heat shock and that was not connected to typical apoptotic markers on their surface.

In summary, neutrophil heat stress is associated with a significant reduction in CD16 expression that modifies the molecular pattern of these cells towards nonphlogistic recognition by macrophages. Although the precise mechanisms and the functional consequences of reduced expression of CD16 remain to be determined, it is tempting to speculate that neutrophil stress may contribute significantly to the anti-inflammatory signalling at inflamed sites. The appear- ance of a CD16-low neutrophil population significantly preceded the development of spontaneous apoptosis and apoptosis-related shedding of CD16. We assume that in vivo the short episodes of extremely high febrile temperatures $\left(39-41^{\circ} \mathrm{C}\right)$ may generate a quick anti-inflammatory response before increased PMNs apoptosis exerts its effect. Furthermore, the novel finding that altered expression of a membrane glycoprotein correlates with the heat stress event indicates that cell-specific membrane molecule alterations occur during fever.

\section{Acknowledgments}

The authors are indebted to Dr. Maria Mycielska (Imperial College London, UK) for critical reading of the manuscript and helpful discussions and to Ms. Ewa Marewicz (Jagiellonian University, Kraków) for excellent technical assistance. This work was supported by grants N N303 291934 (to Malgorzata Bzowska) and N N301 031534 (to Krzysztof Guzik) and also partially by Statutory Activity (DS6), all from the Ministry of Science and Higher Education (Warsaw, Poland). The Faculty of Biochemistry, Biophysics and Biotechnology of the Jagiellonian University is a beneficiary of the structural funds from the European Union (Grant no: POIG.02.01.0012-064/08-“Molecular biotechnology for health".

\section{References}

[1] C. Nathan, "Neutrophils and immunity: challenges and opportunities," Nature Reviews Immunology, vol. 6, no. 3, pp. 173-182, 2006.

[2] S. D. Kobayashi, J. M. Voyich, A. R. Whitney, and F. R. DeLeo, "Spontaneous neutrophil apoptosis and regulation of cell survival by granulocyte macrophage-colony stimulating factor," Journal of Leukocyte Biology, vol. 78, no. 6, pp. 14081418, 2005.

[3] S. François, J. El Benna, P. M. C. Dang, E. Pedruzzi, M. A. Gougerot-Pocidalo, and C. Elbim, "Inhibition of neutrophil apoptosis by TLR agonists in whole blood: involvement of the phosphoinositide 3-kinase/Akt and NF- $\kappa \mathrm{B}$ signaling pathways, leading to increased levels of Mcl-1, A1, and phosphorylated bad," Journal of Immunology, vol. 174, no. 6, pp. 3633-3642, 2005.

[4] R. E. Voll, M. Herrmann, E. A. Roth, C. Stach, J. R. Kalden, and I. Girkontaite, "Immunosuppressive effects of apoptotic cells,” Nature, vol. 390, no. 6658, pp. 350-351, 1997.

[5] K. Lauber, S. G. Blumenthal, M. Waibel, and S. Wesselborg, "Clearance of apoptotic cells: getting rid of the corpses," Molecular Cell, vol. 14, no. 3, pp. 277-287, 2004.

[6] L. M. Stuart and R. A. B. Ezekowitz, "Phagocytosis: elegant complexity," Immunity, vol. 22, no. 5, pp. 539-550, 2005.

[7] J. Savill, I. Dransfield, C. Gregory, and C. Haslett, "A blast from the past: clearance of apoptotic cells regulates immune responses," Nature Reviews Immunology, vol. 2, no. 12, pp. 965-975, 2002.

[8] M. L. Albert, "Death-defying immunity: do apoptotic cells influence antigen processing and presentation?" Nature Reviews Immunology, vol. 4, no. 3, pp. 223-231, 2004.

[9] U. A. Hirt and M. Leist, "Rapid, noninflammatory and PSdependent phagocytic clearance of necrotic cells," Cell Death and Differentiation, vol. 10, no. 10, pp. 1156-1164, 2003. 
[10] G. Brouckaert, M. Kalai, D. V. Krysko et al., "Phagocytosis of necrotic cells by macrophages is phosphatidylserine dependent and does not induce inflammatory cytokine production," Molecular Biology of the Cell, vol. 15, no. 3, pp. 1089-1100, 2004.

[11] L. Zitvogel, N. Casares, M. O. Péquignot, N. Chaput, M. L. Albert, and G. Kroemer, "Immune response against dying tumor cells," Advances in Immunology, vol. 84, pp. 131-179, 2004.

[12] N. Casares, M. O. Pequignot, A. Tesniere et al., "Caspasedependent immunogenicity of doxorubicin-induced tumor cell death," Journal of Experimental Medicine, vol. 202, no. 12, pp. 1691-1701, 2005.

[13] M. B. Torchinsky, J. Garaude, A. P. Martin, and J. M. Blander, "Innate immune recognition of infected apoptotic cells directs T 17 cell differentiation," Nature, vol. 458, no. 7234, pp. 78-82, 2009.

[14] D. R. Green, T. Ferguson, L. Zitvogel, and G. Kroemer, "Immunogenic and tolerogenic cell death," Nature Reviews Immunology, vol. 9, no. 5, pp. 353-363, 2009.

[15] J. D. Hasday and I. S. Singh, "Fever and the heat shock response: distinct, partially overlapping processes," Cell Stress and Chaperones, vol. 5, no. 5, pp. 471-480, 2000.

[16] D. A. Parsell and S. Lindquist, "The function of heat-shock proteins in stress tolerance: degradation and reactivation of damaged proteins," Annual Review of Genetics, vol. 27, pp. 437-496, 1993.

[17] B. Bukau and A. L. Horwich, "The Hsp70 and Hsp60 chaperone machines," Cell, vol. 92, no. 3, pp. 351-366, 1998.

[18] J. Buchner, "Hsp90 \& Co.—a holding for folding," Trends in Biochemical Sciences, vol. 24, no. 4, pp. 136-141, 1999.

[19] B. Bukau, J. Weissman, and A. Horwich, "Molecular chaperones and protein quality control," Cell, vol. 125, no. 3, pp. 443$451,2006$.

[20] M. Jäättelä, D. Wissing, P. A. Bauer, and G. C. Li, "Major heat shock protein hsp70 protects tumor cells from tumor necrosis factor cytotoxicity," The EMBO Journal, vol. 11, no. 10, pp. 3507-3512, 1992.

[21] P. Mehlen, K. Schulze-Osthoff, and A. P. Arrigo, "Small stress proteins as novel regulators of apoptosis. Heat shock protein 27 blocks Fas/APO-1- and staurosporine-induced cell death," Journal of Biological Chemistry, vol. 271, no. 28, pp. 16510 16514, 1996.

[22] S. N. C. Liossis, X. Z. Ding, J. G. Kiang, and G. C. Tsokos, "Overexpression of the heat shock protein 70 enhances the TCR/CD3- and Fas/Apo-1/CD95-mediated apoptotic cell death in Jurkat T cells," Journal of Immunology, vol. 158, no. 12 , pp. 5668-5675, 1997.

[23] H. M. Beere, B. B. Wolf, K. Cain et al., "Heat-shock protein 70 inhibits apoptosis by preventing recruitment of procaspase- 9 to the Apaf-1 apoptosome," Nature Cell Biology, vol. 2, no. 8, pp. 469-475, 2000.

[24] A. Nagarsekar, R. S. Greenberg, N. G. Shah, I. S. Singh, and J. D. Hasday, "Febrile-range hyperthermia accelerates caspase-dependent apoptosis in human neutrophils," Journal of Immunology, vol. 181, no. 4, pp. 2636-2643, 2008.

[25] R. Kettritz, M. Choi, B. Salanova, M. Wellner, S. Rolle, and F. C. Luft, "Fever-like temperatures affect neutrophil NF- $\kappa$ B signaling, apoptosis, and ANCA-antigen expression," Journal of the American Society of Nephrology, vol. 17, no. 5, pp. 13451353, 2006.
[26] T. K. Davtyan, G. S. Hakopyan, S. A. Avetisyan, and N. R. Mkrtchyan, "Impaired endotoxin tolerance induction in patients with familial Mediterranean fever," Pathobiology, vol. 73, no. 1, pp. 26-39, 2006.

[27] T. K. Davtyan, G. S. Hakobyan, S. A. Avetisyan, and V. A. Harutyunyan, "Engaging anti-inflammatory mechanisms and triggering inflammatory effector apoptosis during Familial Mediterranean Fever attack," Inflammation Research, vol. 57, no. 2, pp. 65-74, 2008.

[28] M. Choi, B. Salanova, S. Rolle et al., "Short-term heat exposure inhibits inflammation by abrogating recruitment of and nuclear factor- $\kappa \mathrm{B}$ activation in neutrophils exposed to chemotactic cytokines," American Journal of Pathology, vol. 172, no. 2, pp. 367-377, 2008.

[29] P. Rice, E. Martin, J. R. He et al., "Febrile-range hyperthermia augments neutrophil accumulation and enhances lung injury in experimental gram-negative bacterial pneumonia," Journal of Immunology, vol. 174, no. 6, pp. 3676-3685, 2005.

[30] K. Guzik, M. Bzowska, J. Dobrucki, and J. Pryjma, "Heatshocked monocytes are resistant to Staphylococcus aureusinduced apoptotic DNA fragmentation due to expression of HSP72," Infection and Immunity, vol. 67, no. 8, pp. 4216-4222, 1999.

[31] K. Guzik, M. Bzowska, J. Smagur et al., "A new insight into phagocytosis of apoptotic cells: proteolytic enzymes divert the recognition and clearance of polymorphonuclear leukocytes by macrophages," Cell Death and Differentiation, vol. 14, no. 1, pp. 171-182, 2007.

[32] S. J. Martin, C. P. M. Reutelingsperger, A. J. McGahon et al., "Early redistribution of plasma membrane phosphatidylserine is a general feature of apoptosis regardless of the initiating stimulus: inhibition by overexpression of Bcl-2 and Abl," Journal of Experimental Medicine, vol. 182, no. 5, pp. 15451556, 1995.

[33] S. Brown, I. Heinisch, E. Ross, K. Shaw, C. O. Buckley, and J. Savill, "Apoptosis disables CD31-mediated cell detachment from phagocytes promoting binding and engulfment," Nature, vol. 418, no. 6894, pp. 200-203, 2002.

[34] S. J. Gardai, K. A. McPhillips, S. C. Frasch et al., "Cellsurface calreticulin initiates clearance of viable or apoptotic cells through trans-activation of LRP on the phagocyte," Cell, vol. 123, no. 2, pp. 321-334, 2005.

[35] I. Dransfield, A. M. Buckle, J. S. Savill, A. McDowall, C. Haslett, and N. Hogg, "Neutrophil apoptosis is associated with a reduction in CD16 (Fc $\gamma$ RIII) expression," Journal of Immunology, vol. 153, no. 3, pp. 1254-1263, 1994.

[36] M. F. Tosi and H. Zakem, "Surface expression of Fc $y$ receptor III (CD16) on chemoattractant-stimulated neutrophils is determined by both surface shedding and translocation from intracellular storage compartments," Journal of Clinical Investigation, vol. 90, no. 2, pp. 462-470, 1992.

[37] T. Mitchell, A. Lo, M. R. Logan, P. Lacy, and G. Eitzen, "Primary granule exocytosis in human neutrophils is regulated by Rac-dependent actin remodeling," American Journal of Physiology, vol. 295, no. 5, pp. C1354-C1365, 2008.

[38] M. J. Cotter, A. K. Zaiss, and D. A. Muruve, "Neutrophils interact with adenovirus vectors via Fc receptors and complement receptor 1," Journal of Virology, vol. 79, no. 23, pp. 1462214631, 2005.

[39] P. J. Middelhoven, J. D. Van Buul, P. L. Hordijk, and D. Roos, "Different proteolytic mechanisms involved in Fc $\gamma$ RIIIB shedding from human neutrophils," Clinical and Experimental Immunology, vol. 125, no. 1, pp. 169-175, 2001. 
[40] T. W. J. Huizinga, M. De Haas, M. Kleijer, J. H. Nuijens, D. Roos, and K. A. E. G. von dem Borne, "Soluble Fc $\gamma$ receptor III in human plasma originates from release by neutrophils," Journal of Clinical Investigation, vol. 86, no. 2, pp. 416-423, 1990.

[41] K. Triantafilou, M. Triantafilou, S. Ladha et al., "Fluorescence recovery after photobleaching reveals that LPS rapidly transfers from CD14 to hsp70 and hsp90 on the cell membrane," Journal of Cell Science, vol. 114, no. 13, pp. 2535-2545, 2001.

[42] M. Triantafilou, K. Miyake, D. T. Golenbock, and K. Triantafilou, "Mediators of innate immune recognition of bacteria concentrate in lipid rafts and facilitate lipopolysaccharideinduced cell activation," Journal of Cell Science, vol. 115, no. 12, pp. 2603-2611, 2002.

[43] A. Pfeiffer, A. Böttcher, E. Orsó et al., "Lipopolysaccharide and ceramide docking to CD14 provokes ligand-specific receptor clustering in rafts," European Journal of Immunology, vol. 31, no. 11, pp. 3153-3164, 2001.

[44] J. Skrzeczyńska-Moncznik, M. Bzowska, S. Loseke, E. GrageGriebenow, M. Zembala, and J. Pryjma, "Peripheral blood $\mathrm{CD} 14^{\text {high }} \mathrm{CD} 16^{+}$monocytes are main producers of IL-10," Scandinavian Journal of Immunology, vol. 67, no. 2, pp. 152159, 2008.

[45] J. Smagur, K. Guzik, M. Bzowska et al., "Staphylococcal cysteine protease staphopain B (SspB) induces rapid engulfment of human neutrophils and monocytes by macrophages," Biological Chemistry, vol. 390, no. 4, pp. 361-371, 2009.

[46] J. Smagur, K. Guzik, L. Magiera et al., "A new pathway of staphylococcal pathogenesis: apoptosis-like death induced by staphopain B in human neutrophils and monocytes," Journal of Innate Immunity, vol. 1, no. 2, pp. 98-108, 2009.

[47] J. Stöckl, O. Majdic, W. F. Pickl et al., "Granulocyte activation via a binding site near the C-terminal region of complement receptor type $3 \alpha$-chain (CD11b) potentially involved in intramembrane complex formation with glycosylphosphatidylinositol-anchored Fc $\gamma$ RIIIB (CD16) molecules," Journal of Immunology, vol. 154, no. 10, pp. 5452-5463, 1995.

[48] J. El-Benna, P. M. C. Dang, and M. A. Gougerot-Pocidalo, "Priming of the neutrophil NADPH oxidase activation: role of p47phox phosphorylation and NOX2 mobilization to the plasma membrane," Seminars in Immunopathology, vol. 30, no. 3, pp. 279-289, 2008.

[49] S. D. Swain, T. T. Rohn, and M. T. Quinn, "Neutrophil priming in host defense: role of oxidants as priming agents," Antioxidants and Redox Signaling, vol. 4, no. 1, pp. 69-83, 2002.

[50] G. Kirkali, M. Tunca, S. Genc, P. Jaruga, and M. Dizdaroglu, "Oxidative DNA damage in polymorphonuclear leukocytes of patients with familial Mediterranean fever," Free Radical Biology and Medicine, vol. 44, no. 3, pp. 386-393, 2008. 


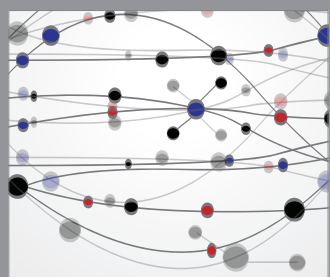

The Scientific World Journal
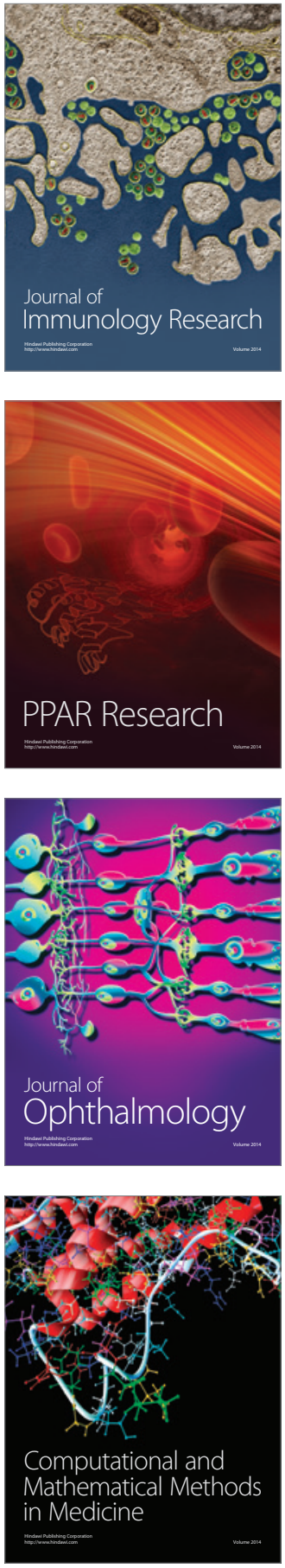

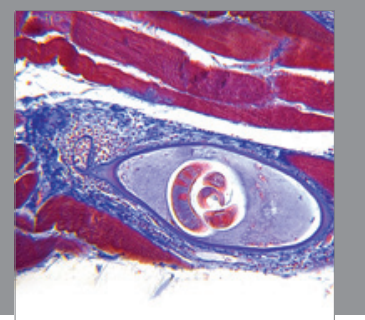

Gastroenterology

Research and Practice
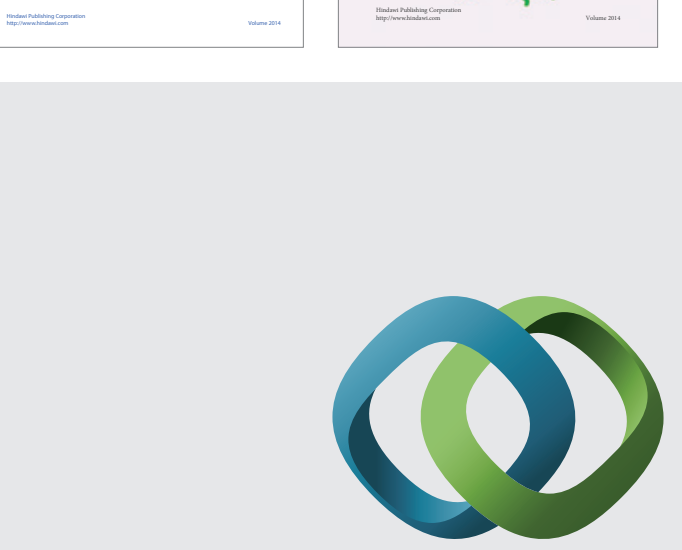

\section{Hindawi}

Submit your manuscripts at

http://www.hindawi.com
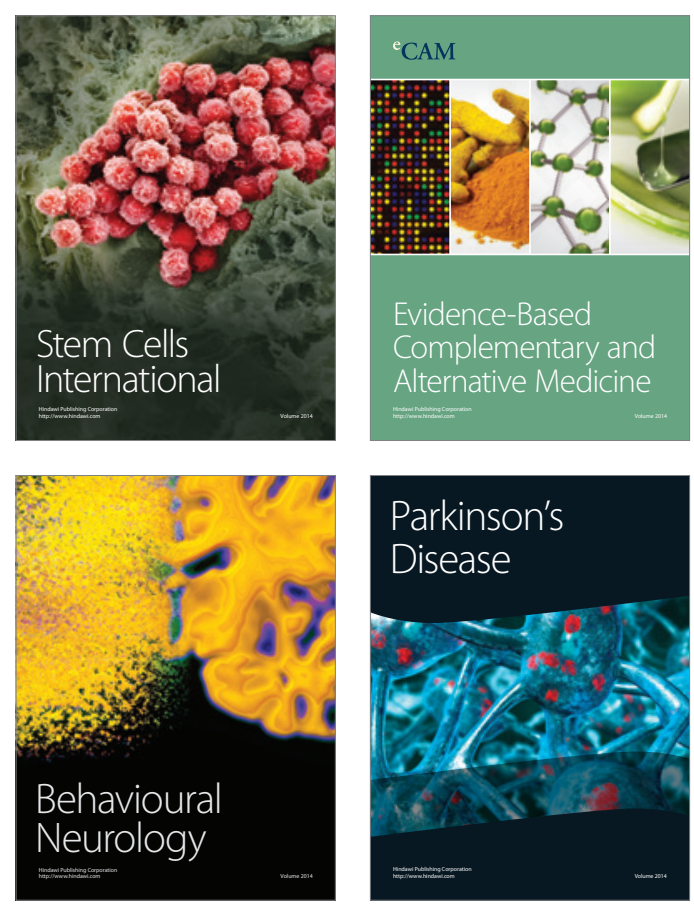

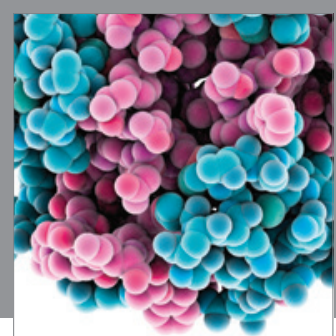

Journal of
Diabetes Research

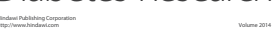

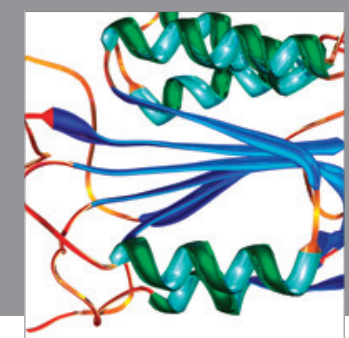

Disease Markers
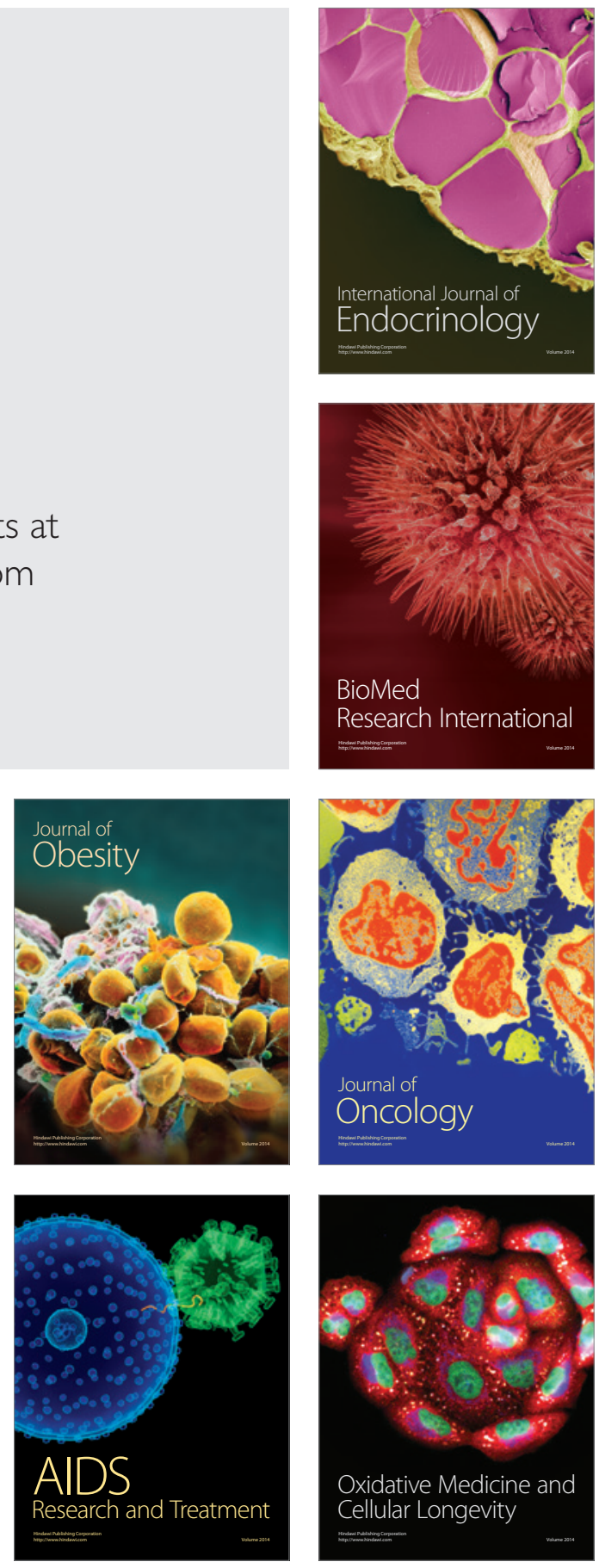